\title{
AN ECONOMIC RISK ANALYSIS OF WEED-SUPPRESSIVE RICE CULTIVARS IN CONVENTIONAL RICE PRODUCTION
}

\author{
K. BRADLEY WATKINS* \\ University of Arkansas Rice Research \& Extension Center, Stuttgart, Arkansas \\ DAVID R. GEALY \\ Dale Bumpers Rice Research Center, Stuttgart, Arkansas
}

MERLE M. ANDERS

University of Arkansas Rice Research \& Extension Center, Stuttgart, Arkansas

RANJITSINH U. MANE

University of Arkansas at Pine Bluff, Department of Agriculture, Pine Bluff, Arkansas

\begin{abstract}
Weed-suppressive rice cultivars have the potential to reduce heavy reliance on synthetic herbicides in rice production. However, the economics of using weed-suppressive rice cultivars in conventional rice systems have not been fully evaluated. This study uses simulation and stochastic efficiency with respect to a function to rank weed-suppressive and weed-nonsuppressive rice cultivars under alternative herbicide intensity levels based on their certainty equivalents mapped across increasing levels of absolute risk aversion. The results indicate risk-averse rice producers would prefer to grow weed-suppressive cultivars using less herbicide inputs than what would be used to grow weed-nonsuppressive rice cultivars.
\end{abstract}

Keywords. Certainty equivalent, cultivar, herbicide, net returns, rice, risk premium, weed suppressive

JEL Classifications. Q12, Q16

\section{Introduction}

Weeds are a major constraint to rice production both in the developed and the developing world. In the developed world, weeds in rice and other cereal crops are controlled primarily with synthetic herbicides. Herbicide use is routine in most cereal crop breeding trials, precluding selection for weed-suppressive ability (Worthington and Reberg-Horton, 2013). In the United States, most rice

The authors would like to thank Howard Black, Bill Luebke, Ashley Smith, Kenneth Hale, Gordon Miller, Alex Humphries, and Galen Branch for technical assistance. The authors also wish to thank the three anonymous reviewers for their constructive comments.

*Corresponding author’s e-mail: kbwatki@uark.edu 
cultivars are not inherently weed suppressive and require substantial herbicide inputs to achieve agronomic and economic viability (Gealy and Moldenhauer, 2012; Gealy and Yan, 2012; Gealy et al., 2003, 2014). In the developing world, particularly in low-input and subsistence farming settings, weeds in rice production are controlled primarily through manual weeding because of the high cost of herbicides (Saito, 2014; Saito and Futakuchi, 2014) or lack of herbicide availability (Guo et al., 2009). Manual weeding is very labor intensive, and large losses in yield from weed infestations are possible when labor availability is limiting (Guo et al., 2009; Saito and Futakuchi, 2014).

Intensive herbicide application in rice production also has potential drawbacks. Apart from its cost, intensive herbicide application can result in development of herbicide-resistant weeds, environmental pollution, and adverse human health interactions (Duke et al., 2000; He et al., 2009; Kong et al., 2011; Xuan et al., 2004). Because of these shortcomings, many have proposed using weed-suppressive or allelopathic cultivars as an alternative or supplement that could reduce the present heavy reliance on traditional synthetic herbicides (Gealy et al., 2003; Guo et al., 2009; Khanh, Zuan, and Chung, 2007; Kong et al., 2011; Pheng et al., 2009; Worthington and Reberg-Horton, 2013; Xuan et al., 2004).

Weed-suppressive rice cultivars have been shown to produce commercially acceptable yields and reduce weed impacts (Chen, Hu, and Kong, 2008; Gealy and Yan, 2012; Gealy et al., 2003, 2014; Gealy, Moldenhauer, and Jia, 2013; Kong et al., 2008). However, the economic benefits of using weed-suppressive rice cultivars have not been fully evaluated. Only one study has conducted an economic analysis of weed-suppressive rice cultivars in a rice production system (Gealy et al., 2003). This study evaluated the barnyard grass suppressive ability of four U.S. rice cultivars and three Asian rice cultivars under varying propanil rates. The authors calculated net returns above production costs for each cultivar. They found the Asian cultivars consistently suppressed barnyard grass more and produced higher rough rice yields than the U.S. cultivars. However, the Asian cultivars also had lower milling quality than their U.S. counterparts. The economic advantage of using these cultivars in conjunction with lower herbicide rates was thus reduced when lower milling quality was taken into account. Thus, the authors concluded grain quality characteristics of weedsuppressive cultivars must be improved.

The objective of this study is to evaluate the profitability and risk preferences of using weed-suppressive rice cultivars in conventional rice production. Stochastic returns above production costs are simulated by cultivar-weed management combination using grain yields and herbicide application data obtained from a 3-year agronomic study (Gealy et al., 2014). The 3-year study evaluated both rice productivity and weed control for seven different rice cultivars under three different weed management levels (low, medium, and high herbicide inputs). Rice grain yields and rice prices adjusted for milling quality are simulated by cultivar-weed management combination and are then used to construct stochastic returns above production costs for each combination. Stochastic 
efficiency with respect to a function (SERF) is used to rank rice cultivar-weed management combinations based on their certainty equivalents (CEs) mapped across a range of increasing absolute risk aversion coefficients (ARACs).

\section{Methods}

\subsection{Summary of Agronomic Study}

The agronomic study on which this analysis is based was conducted at the University of Arkansas Rice Research and Extension Center near Stuttgart, Arkansas, during the years 2009, 2010, and 2011. Seven rice cultivars (three "weed suppressive" and four "weed nonsuppressive") were evaluated in the study. The indica lines, 'PI 312777' (T65*2/Taichung Native 1) and 'Rondo' (Yan and McClung, 2010), and the proprietary commercial Clearfield hybrid, 'CLXL729', were included for their weed-suppressive potential; and the mediumgrain type, 'Bengal' (Linscombe et al., 1993), and long-grain types, 'Wells' (Moldenhauer et al., 2007), 'Lemont' (Bollich et al., 1985), and 'CL171AR' were included as "nonsuppressive" commercial standards. The experimental design for this study was a split-split-plot with four replicate blocks. The main plots were two irrigation systems (flood and furrow), the subplots were the seven rice cultivars, and the sub-subplots were the three weed management levels (low, medium, and high) varying by herbicide type and intensity. Although the agronomic study had two irrigation treatments (flood and furrow), rice yields under the furrow irrigation treatment were too low across rice cultivars, weed management treatments, and years to generate meaningful economic comparisons. This was particularly true of 2010 in which furrow irrigation resulted in complete crop failure because of drought and heat stress (Gealy et al., 2014). Thus, the agronomic data used in the present economic study are based exclusively on the flood treatment data only.

The plot area was managed in a 1-year rice/1-year soybean rotation and received a broadcast application of $20 \mathrm{lb}$./acre $\mathrm{P}$ as triple superphosphate and 50 $\mathrm{lb}$./acre $\mathrm{K}$ as potassium chloride (muriate of potash) each year after disking and floating (land leveling) of the ground prior to crop planting. All cultivars were seeded using $100 \mathrm{lb}$./acre of seed with the exception of CLXL729, which received $30.5 \mathrm{lb}$./acre of seed. Natural rainfall was supplemented with flush irrigation as necessary to maintain healthy rice plants from germination to the four- to fiveleaf stage at which time nitrogen fertilizer was applied at $100 \mathrm{lb}$./acre in the form of urea. A 4-inch-deep permanent flood was established immediately following $\mathrm{N}$ application. For more detailed information regarding the cultural management used in the study, see Gealy et al. (2014).

\subsection{Establishment of Weed Management Levels}

High, medium, and low weed management levels were established by applying different rates and timings of herbicide as indicated in Table 1. Low corresponded to extremely low herbicide inputs (i.e., far below recommended rates; intended 
Table 1. Herbicide Treatments and Timings by Year and Weed Management

\begin{tabular}{|c|c|c|c|c|c|}
\hline Year & $\begin{array}{l}\text { Weed } \\
\text { Management }\end{array}$ & Preherbicide & Postherbicide & $\begin{array}{l}\text { Additional } \\
\text { Postherbicide }\end{array}$ & $\begin{array}{l}2017 \text { Product } \\
\text { Cost (\$/acre) }\end{array}$ \\
\hline \multirow[t]{3}{*}{2009} & Low & - & $\begin{array}{l}\text { June 29: propanil } \\
\text { @ 0.9992 lb. } \\
\text { active } \\
\text { ingredient } \\
\text { (ai)/acre }\end{array}$ & - & 7.47 \\
\hline & Medium & $\begin{array}{l}\text { June } 2 \text { : } \\
\text { clomazone @ } \\
0.4015 \text { lb. } \\
\text { ai/acre }\end{array}$ & - & - & 17.58 \\
\hline & High & $\begin{array}{l}\text { June } 2 \text { : } \\
\text { clomazone @ } \\
0.4015 \mathrm{lb} . \\
\text { ai/acre }\end{array}$ & - & - & 17.58 \\
\hline \multirow[t]{3}{*}{2010} & Low & $\begin{array}{l}\text { May 27: } \\
\text { glyphosate @ } \\
0.9992 \mathrm{lb} . \\
\text { ai/acre + 1\% } \\
\text { prime oil }\end{array}$ & $\begin{array}{l}\text { July 14:propanil } \\
\text { @ 0.9992 lb. } \\
\text { ai/acre }\end{array}$ & - & 11.73 \\
\hline & Medium & $\begin{array}{l}\text { May 27: } \\
\text { clomazone @ } \\
0.3033 \text { lb. } \\
\text { ai/acre + } \\
\text { glyphosate @ } \\
0.9992 \text { lb. } \\
\text { ai/acre + 1\% } \\
\text { prime oil }\end{array}$ & - & - & 17.55 \\
\hline & High & $\begin{array}{l}\text { May 27: } \\
\text { clomazone @ } \\
0.3033 \mathrm{lb.} \\
\text { ai/acre + } \\
\text { glyphosate @ } \\
0.9992 \mathrm{lb} . \\
\text { ai/acre + 1\% } \\
\text { prime oil }\end{array}$ & $\begin{array}{l}\text { July 14: } \\
\text { quinclorac @ } \\
0.2498 \mathrm{lb} . \\
\text { ai/acre + } \\
\text { fenoxaprop @ } \\
0.0803 \mathrm{lb} . \\
\text { ai/acre + } \\
\text { halosulfuron } \\
\text { @ } 0.0473 \mathrm{lb} . \\
\text { ai/acre }+1 \% \\
\text { prime oil }\end{array}$ & - & 73.54 \\
\hline \multirow[t]{2}{*}{2011} & Low & - & - & $\begin{array}{l}\text { June } 30 \text { : } \\
\text { halosulfuron } \\
\text { @ } 0.0473 \mathrm{lb} . \\
\text { ai/acre + } 1 \% \\
\text { prime oil + } \\
\text { propanil @ } \\
1.9628 \mathrm{lb} . \\
\text { ai/acre }\end{array}$ & 36.88 \\
\hline & Medium & $\begin{array}{l}\text { May 19: } \\
\text { clomazone @ } \\
0.3033 \text { lb. } \\
\text { ai/acre }\end{array}$ & - & $\begin{array}{l}\text { June } 30 \text { : } \\
\text { halosulfuron } \\
\text { @ } 0.0473 \mathrm{lb} \text {. } \\
\text { ai/acre }+1 \% \\
\text { prime oil }\end{array}$ & 35.49 \\
\hline
\end{tabular}


Table 1. Continued

\begin{tabular}{|c|c|c|c|c|c|}
\hline Year & $\begin{array}{l}\text { Weed } \\
\text { Management }\end{array}$ & Preherbicide & Postherbicide & $\begin{array}{l}\text { Additional } \\
\text { Postherbicide }\end{array}$ & $\begin{array}{l}2017 \text { Product } \\
\text { Cost (\$/acre) }\end{array}$ \\
\hline & High & $\begin{array}{l}\text { May 19: } \\
\text { clomazone @ } \\
0.3033 \mathrm{lb} . \\
\text { ai/acre }\end{array}$ & $\begin{array}{l}\text { June 24: } \\
\text { quinclorac @ } \\
0.2498 \mathrm{lb} . \\
\text { ai/acre + } \\
\text { fenoxaprop @ } \\
0.0937 \mathrm{lb} . \\
\text { ai/acre + 1\% } \\
\text { prime oil }\end{array}$ & $\begin{array}{l}\text { June } 30 \text { : } \\
\text { halosulfuron } \\
\text { @ } 0.0473 \mathrm{lb} \text {. } \\
\text { ai/acre }+1 \% \\
\text { prime oil }\end{array}$ & 75.62 \\
\hline
\end{tabular}

to facilitate excessive weed competitiveness against rice). ${ }^{1}$ Medium and high corresponded to extension/manufacturer recommendations (Scott et al., 2012), with medium representing less than optimal herbicide treatments (i.e., limited number of applications at rates recommended for weed control in lightly infested fields), and high representing near-maximum rates of one or more herbicide products expected to achieve excellent weed control in heavily infested fields. The specific herbicides and rates used for medium and high management were selected based on periodic inspection of the weed populations in the plots throughout each growing season. The herbicide-resistant cultivars, CLXL729 and CL171AR, were used as proxies for hybrid and conventional inbred rice cultivars, respectively, and thus were not grown under "Clearfield" management protocols. Both cultivars are resistant to imidazoline herbicides, which allows for greater control of red rice without killing rice growing in the field. Our analysis in this study does not take into account any production or economic ramifications of this herbicide-resistant technology.

\subsection{Simulated Rice Grain Yields}

Yield distributions by rice cultivar and weed management strategy (low, medium, and high weed management) were simulated using Simulation and Econometrics to Analyze Risk (SIMETAR) (Richardson, Schumann, and Feldman, 2008). Multivariate empirical (MVE) distributions were used to simulate rice yield distributions of 500 iterations each for the seven cultivars evaluated under high, medium, and low weed management. An MVE distribution simulates random values from a frequency distribution made up of actual historical data and has been shown to appropriately correlate random variables based on their historical correlation (Richardson, Klose, and Gray, 2000). Ignoring correlation of random variables biases the variance for output variables either upward

1 A low-herbicide treatment was used in this study in place of a zero-herbicide treatment to remove the risk of complete crop failure and the resulting loss of experimental data from occurring in any of the three experimental years. 
or downward. Variance for an output variable is overestimated if a negative correlation between enterprises is ignored and is underestimated if a positive correlation between enterprises is ignored (Richardson, Klose, and Gray, 2000). Parameters for the MVE distribution include the means, deviations from the mean or trend expressed as a fraction of each variable, and the correlation among variables. The MVE distribution is used in instances where data observations are too few to estimate parameters for another distribution (Pendell et al., 2006). The MVE distribution is also a closed-form distribution, in that it eliminates the possibility of simulated values exceeding values observed in history (Ribera, Hons, and Richardson, 2004). For a more in-depth explanation of the MVE distribution, see Richardson, Klose, and Gray (2000).

Rice yield distributions for each of the seven cultivars were simulated under high, medium, and low weed management using rough rice yields adjusted to $12 \%$ moisture content from the 3 -year cultivar by weed management study. The yield data in the study were replicated four times each year for all three weed management levels, and all replicated data were used in the simulations. Percent deviations from the mean were used in the MVE distribution simulations.

Summary statistics of simulated rice yields are presented by cultivar and weed management in Table 2. Two-sample Hotelling $T^{2}$ test statistics are also reported in Table 2. The two-sample Hotelling $T^{2}$ test is a multivariate distribution test to determine if the historical yield matrix and the simulated yield matrix have equivalent mean vectors (Richardson, Schumann, and Feldman, 2008). In each instance, the null hypotheses that the mean vectors are equal could not be rejected. Results of other statistical multivariate tests (the Box's $M$ test and the complete homogeneity test; Richardson, Schumann, and Feldman, 2008) showed no statistical differences existed between covariance matrices of simulated yields and actual yields for each weed management scenario, indicating the multivariate distributions of the actual yield data are being simulated appropriately.

Correlation coefficients of simulated rice cultivar yields and historical rice cultivar yields were tested to determine if they were not statistically different using Student's $t$-test statistics (Table 3 ). If a correlation coefficient for two simulated variables is statistically different from the respective historical correlation coefficient, the Student's $t$-test statistic will exceed the critical value. Student's $t$-test statistics exceeding the critical value are displayed in bold in Table 3. In the majority of comparisons, correlation coefficients are not statistically different between historical and simulated rice yields. Low and high weed management have the largest number of instances where simulated and actual correlation coefficients are significantly different (5 out of 21 test comparisons for high weed management; 7 out of 21 comparisons for low weed management at the $95 \%$ confidence level). Although there are instances where actual and simulated correlation coefficients are significantly different, the direction (sign) of correlation between cultivars in the actual data is captured and maintained in the simulated data. 
Table 2. Summary Statistics of Simulated Rice Yields by Cultivar and Weed Management (bu./acre)

\begin{tabular}{|c|c|c|c|c|c|}
\hline Cultivar & Mean $^{\mathrm{a}}$ & SD & $\mathrm{CV}$ & Minimum & Maximum \\
\hline \multicolumn{6}{|c|}{ High Weed Management } \\
\hline PI 312777 & 116 & 21 & 18 & 72 & 142 \\
\hline Rondo & 116 & 13 & 11 & 100 & 142 \\
\hline CLXL729 & 131 & 27 & 21 & 64 & 162 \\
\hline Bengal & 101 & 32 & 32 & 55 & 147 \\
\hline Wells & 109 & 20 & 18 & 85 & 142 \\
\hline Lemont & 83 & 22 & 27 & 56 & 128 \\
\hline \multirow[t]{2}{*}{ CL171AR } & 86 & 17 & 20 & 49 & 115 \\
\hline & & Test Value & Critical Value & $P$ Value & \\
\hline \multicolumn{2}{|c|}{ Two-sample Hotelling $T^{2}$ test $^{\mathrm{b}}$} & 0.045 & 14.363 & 1.000 & \\
\hline \multicolumn{6}{|c|}{ Medium Weed Management } \\
\hline PI 312777 & 113 & 22 & 20 & 79 & 158 \\
\hline Rondo & 111 & 17 & 15 & 83 & 137 \\
\hline CLXL729 & 109 & 35 & 32 & 34 & 147 \\
\hline Bengal & 91 & 32 & 35 & 31 & 126 \\
\hline Wells & 95 & 28 & 29 & 53 & 138 \\
\hline Lemont & 57 & 17 & 31 & 21 & 85 \\
\hline \multirow[t]{2}{*}{ CL171AR } & 65 & 25 & 38 & 29 & 107 \\
\hline & & Test Value & Critical Value & $P$ Value & \\
\hline Two-sampl & lling $T^{2}$ test $^{\mathrm{b}}$ & 0.013 & 14.363 & 1.000 & \\
\hline \multicolumn{6}{|c|}{ Low Weed Management } \\
\hline PI 312777 & 81 & 31 & 38 & 23 & 128 \\
\hline Rondo & 64 & 23 & 37 & 29 & 122 \\
\hline CLXL729 & 59 & 34 & 57 & 17 & 133 \\
\hline Bengal & 44 & 28 & 64 & 2 & 95 \\
\hline Wells & 39 & 26 & 65 & 1 & 84 \\
\hline Lemont & 16 & 11 & 70 & 1 & 37 \\
\hline CL171AR & 31 & 28 & 92 & 2 & 95 \\
\hline \multirow{2}{*}{\multicolumn{2}{|c|}{ Two-sample Hotelling $\mathrm{T}^{2}$ test $^{\mathrm{b}}$}} & Test Value & Critical Value & $P$ Value & \\
\hline & & 0.036 & 14.363 & 1.000 & \\
\hline
\end{tabular}

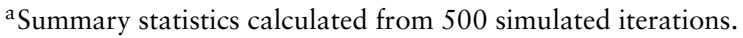

${ }^{\mathrm{b}}$ Confidence level for two-sample Hotelling $T^{2}$ test is $95 \%$.

Note: CV, coefficient of variation; SD, standard deviation.

\subsection{Simulated Rice Milling Yields}

The rice price received by a farmer for a particular rice cultivar is based on the milling quality of that cultivar. Milling quality is measured as total milling yield (weight percent of both whole kernels and broken kernels) and whole kernel yield (percent). For example, a milling yield of $55 / 70$ represents $70 \%$ total milling yield and $55 \%$ whole kernel yield. The difference between total milling yield percent and whole kernel percent represents the percent of broken kernels. The higher the percent of whole kernels, the better the market price received. Consequently, the higher the percent of broken kernels, the lower the market price received. 
Table 3. Student's $t$-Test Statistics for Comparing Correlation Coefficients of Simulated Rice Cultivar Yields to Correlation Coefficients of Historical Rice Cultivar Yields by Weed Management

\begin{tabular}{|c|c|c|c|c|c|c|}
\hline $\begin{array}{l}\text { Confidence level } \\
\text { Critical value }\end{array}$ & & $\begin{array}{l}95 \% \\
1.96 \\
\end{array}$ & & & & \\
\hline \multicolumn{7}{|c|}{ High Weed Management } \\
\hline & Rondo & CLXL729 & Bengal & Wells & Lemont & CL171AR \\
\hline PI 312777 & 4.25 & 0.41 & 0.71 & 0.43 & 1.75 & 1.86 \\
\hline Rondo & & 0.83 & 0.12 & 0.35 & 1.02 & 3.09 \\
\hline CLXL729 & & & 2.64 & 2.80 & 2.01 & 1.01 \\
\hline Bengal & & & & 1.06 & 1.42 & 0.11 \\
\hline Wells & & & & & 1.43 & 0.27 \\
\hline Lemont & & & & & & 0.68 \\
\hline \multicolumn{7}{|c|}{ Medium Weed Management } \\
\hline & Rondo & CLXL729 & Bengal & Wells & Lemont & CL171AR \\
\hline PI 312777 & 0.01 & 0.19 & 0.28 & 0.96 & 0.98 & 0.13 \\
\hline Rondo & & 0.63 & 0.24 & 0.56 & 0.69 & 1.92 \\
\hline CLXL729 & & & 0.83 & 0.51 & 0.82 & 1.41 \\
\hline Bengal & & & & 0.15 & 0.72 & 0.50 \\
\hline Wells & & & & & 0.33 & 1.31 \\
\hline Lemont & & & & & & 0.41 \\
\hline \multicolumn{7}{|c|}{ Low Weed Management } \\
\hline & Rondo & CLXL729 & Bengal & Wells & Lemont & CL171AR \\
\hline PI 312777 & 1.73 & 1.55 & 1.55 & 0.96 & 1.33 & 2.72 \\
\hline Rondo & & 3.09 & 2.15 & 0.89 & 1.31 & 3.30 \\
\hline CLXL729 & & & 1.15 & 2.28 & 1.52 & 1.80 \\
\hline Bengal & & & & 1.22 & 0.88 & 1.40 \\
\hline Wells & & & & & 0.55 & 2.73 \\
\hline Lemont & & & & & & 0.72 \\
\hline
\end{tabular}

aStudent's $t$-test statistics exceeding the critical value are displayed in bold.

Milling quality tends to be lower for weed-suppressive rice cultivars like PI 312777 and Rondo than for other weed-nonsuppressive cultivars. Thus, using the same rice price for all rice cultivars may lead to inflated gross returns (price $\times$ yield) for cultivars with lower milling quality. Gealy et al. (2003) evaluated the economics of weed-suppressive and weed-nonsuppressive rice cultivars with and without milling yield adjusted gross returns. Mean milling yields in their study were not determined experimentally but were acquired by cultivar from the literature and from personal communication.

The present study also uses data from both published and unpublished sources to simulate total whole kernel yields and broken yields for the rice cultivars in the analysis. Milling yield data used to simulate milling quality for CLXL729, Bengal, Wells, Lemont, and CL171AR were collected from Arkansas Rice Performance Trials (ARPT) data for the years 2009-2017 (University of Arkansas Cooperative Extension Service, 2017b). The year 2009 was the first year for which milling 
yield data were collected for Clearfield-hybrids like CLXL729 in the ARPT. Milling yield data were not available for all five cultivars in every year, as many of the cultivars in the study are currently no longer widely grown commercially. Wells was the only rice cultivar with milling yield data for the entire 9-year period. Milling yields for CLXL729 were reported from 2009 to 2015, and milling yields for Bengal were reported from 2009 to 2012. Milling yields were not reported in any of the 9 years for either Lemont or CL171AR.

To deal with these data limitations, total milling yields and whole kernel yields for each year were averaged across all cultivars comprising a particular cultivar type. Cultivar types were then used as proxies for cultivars evaluated in the analysis. Cultivar types included "Clearfield-hybrid rice" (used as a proxy for CLXL729), "medium-grain rice" (used as a proxy for Bengal), and "Clearfield rice" (used as a proxy for CL171AR). Milling yields collected for Wells were also used as proxy milling yields for Lemont, and these two cultivars were classified in this study as "long-grain rice."

Milling yield data used to simulate the milling quality of both PI 312777 and Rondo were not available in the ARPT but were obtained from unpublished Texas rice cultivar research trial data collected in Beaumont, Texas, for the years 2009, 2010, and 2011 (A. McClung, U.S. Department of Agriculture, Agricultural Research Service, Dale Bumpers Rice Research Center [Stuttgart, Arkansas], personal communication, June 2016). Total milling yields and whole kernel yields were replicated for each cultivar from two to four times in each year (two replicates in 2009 and 2010; four replicates in 2011). All replicates were used to simulate milling quality for PI 312777 and Rondo.

Whole kernel yields were subtracted from total milling yields to obtain broken kernel yields for each cultivar type. MVE distributions were used to simulate whole kernel and broken kernel distributions by cultivar type. The ARPT data were used to simulate milling yields for Clearfield-hybrid rice (CLH), mediumgrain rice (MG), long-grain rice (LG), and Clearfield rice (CL), while the Texas rice research trial data were used to simulate milling yields for PI 312777 and Rondo. Percent deviations from the mean were used in both milling yield MVE distribution simulations.

Summary statistics of simulated milling yields are presented by cultivar type and data source in Table 4. Two-sample Hotelling $T^{2}$ test statistics for both simulations are also presented in Table 4. The two-sample Hotelling $T^{2}$ test statistics indicate that the mean vectors of actual and simulated milling yield data matrices are not significantly different from one another. Results of other statistical multivariate tests (the Box's $M$ test and the complete homogeneity test) indicated no statistical differences between covariance matrices of simulated milling yields and covariance matrices of actual milling yields for each data set, indicating the multivariate distributions of actual milling yield data from the ARPT and from Texas are being simulated appropriately. Student's $t$-test statistics comparing the corresponding correlation coefficients of simulated to 
Table 4. Summary Statistics of Simulated Rice Milling Yields Using Arkansas Rice Performance Trial Data and Texas Rice Research Trial Data

\begin{tabular}{|c|c|c|c|c|c|}
\hline Cultivar-Milling & Mean $^{\mathrm{a}}$ & SD & $\mathrm{CV}$ & Minimum & Maximum \\
\hline \multicolumn{6}{|c|}{ Arkansas Rice Performance Trial Data } \\
\hline $\mathrm{CLH}^{\mathrm{b}}-\mathrm{WK}^{\mathrm{c}}$ & 57.7 & 4.1 & 7.2 & 51.0 & 64.0 \\
\hline CLH-BK & 12.2 & 3.6 & 29.8 & 7.5 & 18.0 \\
\hline MG-WK & 60.3 & 2.8 & 4.6 & 56.0 & 65.0 \\
\hline MG-BK & 8.9 & 2.5 & 28.1 & 5.0 & 13.5 \\
\hline LG-WK & 56.7 & 3.6 & 6.3 & 52.0 & 62.0 \\
\hline LG-BK & 14.4 & 3.8 & 26.4 & 8.0 & 21.0 \\
\hline CL-WK & 59.5 & 3.3 & 5.5 & 54.0 & 63.3 \\
\hline CL-BK & 10.5 & 2.8 & 26.4 & 6.4 & 15.2 \\
\hline Two-sample Hot & $T^{2}$ test $^{\mathrm{d}}$ & $\begin{array}{l}\text { Test Value } \\
0.039\end{array}$ & $\begin{array}{l}\text { Critical Value } \\
15.874\end{array}$ & $\begin{array}{l}P \text { Value } \\
1.000\end{array}$ & \\
\hline \multicolumn{6}{|c|}{ Texas Rice Research Trial Data } \\
\hline PI 312777-WK & 49.7 & 4.2 & 8.5 & 45.7 & 60.0 \\
\hline PI 312777-BK & 19.2 & 3.9 & 20.6 & 10.1 & 24.4 \\
\hline Rondo-WK & 41.6 & 6.5 & 15.6 & 31.0 & 52.3 \\
\hline Rondo-BK & 21.7 & 5.8 & 27.0 & 13.2 & 31.9 \\
\hline Two-sample Hot & $T^{2}$ test $^{\mathrm{d}}$ & $\begin{array}{l}\text { Test Value } \\
0.002\end{array}$ & $\begin{array}{l}\text { Critical Value } \\
9.616\end{array}$ & $\begin{array}{l}P \text { Value } \\
1.000\end{array}$ & \\
\hline
\end{tabular}

a Summary statistics calculated from 500 simulated iterations.

${ }^{\mathrm{b}} \mathrm{CL}$, Clearfield rice (proxy for CL171AR); CLH, Clearfield-hybrid rice (proxy for CLXL729); LG, longgrain rice (proxy for Wells and Lemont); MG, medium-grain rice (proxy for Bengal).

${ }^{\mathrm{c}} \mathrm{BK}$, broken kernels (percent); WK, whole kernels (percent).

${ }^{\mathrm{d}}$ Confidence level for two-sample Hotelling $T^{2}$ test is $95 \%$.

Note: CV, coefficient of variation; SD, standard deviation.

actual data for the two simulations are presented in Table 5. In the majority of comparisons, no significant differences are found between the correlation matrices of either the actual and simulated ARPT data ( 2 out of 28 comparisons). For the Texas rice research trial data, significant differences are found in 2 of the 7 correlation coefficient comparisons. Although significant differences are found in some instances, the direction (sign) of milling yield correlation between cultivar types in the actual data is captured and maintained in the simulated data.

\subsection{Stochastic Milling Yield Adjusted Rice Prices}

Milling yield adjusted rice price distributions by rice cultivar type were calculated using the following formula:

$$
P_{k l}=W P \times W K_{k l}+B P \times W K_{k l},
$$

where $P_{k l}$ is the rice price for cultivar type $k$ and iteration $l(\$ /$ bu.); $k=1$ to 6 cultivar types (CHY, MG, LG, CL, PI 312777, and Rondo); $l=1-500$ simulated iterations; $W P$ is the rice whole kernel price $\left(\$ / b u\right.$.); $W K_{k l}$ is the rice whole kernel yield for cultivar type $k$ and iteration $l$ (percent); $B P$ is the rice broken kernel price 
Table 5. Student's $t$-Test Statistics for Comparing Correlation Coefficients of Simulated Rice Milling Yields to Correlation Coefficients of Historical Rice Milling Yields, Arkansas Rice Performance Trial and Texas Rice Research Trial Data

\begin{tabular}{|c|c|c|c|c|c|c|c|}
\hline $\begin{array}{l}\text { Confidence level } \\
\text { Critical value }\end{array}$ & & $\begin{array}{l}95 \% \\
1.96\end{array}$ & & & & & \\
\hline \multicolumn{8}{|c|}{ Arkansas Rice Performance Trial Data } \\
\hline & CLH-BK & MG-WK & MG-BK & LG-WK & LG-BK & CL-WK & CL-BK \\
\hline $\mathrm{CLH}^{\mathrm{a}}-\mathrm{WK}^{\mathrm{b}}$ & 0.97 & 1.11 & 1.01 & 1.58 & 1.08 & 1.11 & 0.75 \\
\hline CLH-BK & & 1.11 & 1.59 & 1.88 & 1.84 & 1.41 & 1.30 \\
\hline MG-WK & & & 0.96 & 1.69 & 0.37 & 1.23 & 0.56 \\
\hline MG-BK & & & & 2.12 & 0.89 & 1.67 & 1.41 \\
\hline LG-WK & & & & & 1.53 & 2.29 & 1.96 \\
\hline LG-BK & & & & & & 1.66 & 1.42 \\
\hline CL-WK & & & & & & & 1.61 \\
\hline \multicolumn{8}{|c|}{ Texas Rice Research Trial Data } \\
\hline & \multicolumn{3}{|c|}{ PI 312777-BK } & \multicolumn{2}{|c|}{ Rondo-WK } & \multicolumn{2}{|c|}{ Rondo-BK } \\
\hline PI 312777-WK & \multirow{3}{*}{\multicolumn{2}{|c|}{1.60}} & & \multicolumn{2}{|c|}{2.40} & \multicolumn{2}{|c|}{1.99} \\
\hline PI 312777-BK & & & & \multicolumn{2}{|c|}{1.31} & \multicolumn{2}{|c|}{0.89} \\
\hline Rondo-WK & & & & & & \multicolumn{2}{|c|}{1.89} \\
\hline
\end{tabular}

${ }^{a}$ CL, Clearfield rice (proxy for CL171AR); CLH, Clearfield-hybrid rice (proxy for CLXL729); LG, longgrain rice (proxy for Wells and Lemont); MG, medium-grain rice (proxy for Bengal).

${ }^{\mathrm{b}} \mathrm{BK}$, broken kernels (percent); WK, whole kernels (percent).

'Student's t-test statistics exceeding the critical value are displayed in bold.

(\$/bu.); and $B K_{k l}$ is the rice whole kernel yield for cultivar type $k$ and iteration $l$ (percent).

The rice whole kernel price (WP) and the rice broken kernel price (BP) in equation (1) were calculated using the following equations:

$$
\begin{gathered}
W P=\frac{R P}{0.55+0.60 \times(0.70-0.55)}, \\
B P=0.60 \times W P,
\end{gathered}
$$

where $R P$ is the price received for Arkansas rice (\$/bu.), and WP and $B P$ are as defined previously. Equation (2) calculates the rice whole kernel price assuming an industry standard milling yield of 55/70 (70\% total milling yield; $55 \%$ whole kernel yield) and assuming the rice broken kernel price is $60 \%$ of the value of the rice whole kernel price. Conversely, the rice broken kernel price $(B P)$ calculated in equation (3) is $60 \%$ of the rice whole kernel price (WP). The value used for $R P$ in equation (2) is $\$ 5.57 / \mathrm{bu}$. and denotes the 5 -year average price received for Arkansas rice for the period 2012-2016 (U.S. Department of Agriculture, National Agricultural Statistics Service, 2018). Using this price, the values calculated for $W P$ and $B P$ are $\$ 8.70 / \mathrm{bu}$. and $\$ 5.22 / \mathrm{bu}$., respectively. 
Table 6. Summary Statistics of Simulated Rice Prices by Rice Type (\$/bu.)

\begin{tabular}{llllll}
\hline \hline Rice Type & Mean $^{\mathrm{a}}$ & SD & CV & Minimum & Maximum \\
\hline CLH $^{\mathrm{b}}$ & 5.66 & 0.18 & 3.3 & 5.25 & 5.97 \\
MG & 5.71 & 0.19 & 3.3 & 5.29 & 6.22 \\
LG & 5.69 & 0.19 & 3.3 & 5.22 & 6.15 \\
CL & 5.72 & 0.16 & 2.7 & 5.27 & 5.97 \\
PI 312777 & 5.32 & 0.21 & 3.9 & 4.83 & 6.08 \\
Rondo & 4.75 & 0.30 & 6.2 & 3.82 & 5.38 \\
\hline \hline
\end{tabular}

aSummary statistics calculated from 500 simulated iterations.

${ }^{\mathrm{b}} \mathrm{CL}$, Clearfield rice (proxy for CL171AR); CLH, Clearfield-hybrid rice (proxy for CLXL729); LG, longgrain rice (proxy for Wells and Lemont); MG, medium-grain rice (proxy for Bengal).

Note: CV, coefficient of variation; SD, standard deviation.

The calculated values for WP and $B P$ are used in equation (1) to calculate milling yield adjusted rice price distributions by cultivar type. Summary statistics of simulated milling yield adjusted rice prices are presented by rice cultivar type in Table 6. Lower milling quality of PI 312777 and Rondo is reflected by lower rice prices for these two cultivar types on average relative to the other cultivar types. The mean prices for PI 312777 and Rondo reported in Table 6 (\$5.32/bu. and $\$ 4.75 /$ bu., respectively) are approximately the same as or below the minimum prices reported for CLH, MG, LG, and CL in Table $6(\$ 5.25 / \mathrm{bu}$. for CLH, $\$ 5.29 / \mathrm{bu}$. for MG, $\$ 5.22 / \mathrm{bu}$. for LG, and $\$ 5.27 / \mathrm{bu}$. for CL).

\subsection{Stochastic Net Returns}

Stochastic net returns were generated by rice cultivar and weed management level using the following equation:

$$
\text { NRijkl }=[(P k l-u) \times Y i j k l]-C j,
$$

where $N R_{i j k l}$ is the net return to operating costs for cultivar $i$, weed management $j$, cultivar type $k$, and iteration $l$ (\$/acre); $i=1$ to 7 rice cultivars; $j=1$ to 3 weed management levels (low, medium, and high); $k=1$ to 6 cultivar types (CHY, MG, LG, CL, PI 312777, and Rondo); $l=1$ to 500 simulated iterations; $P_{k l}$ is the simulated milling quality adjusted price for cultivar type $k$ and iteration $l(\$ / b u$.); $u$ is the sum of per unit custom harvest charges associated with grain drying $(\$ 0.40 / \mathrm{bu}$.$) , hauling (\$ 0.22 / \mathrm{bu}$.$) , and rice research$ and promotion board checkoff $(\$ 0.014 / \mathrm{bu}$.) subtracted from the simulated rice price; $Y_{i j k l}$ is the simulated rice yield for cultivar $i$, weed management $j$, cultivar type $k$, and iteration $l$ (bu./acre); and $C_{j}$ is the average variable production costs over the 3-year study period for weed management $j$ (in 2017 dollars per acre).

Variable production costs in the equation $\left(C_{j}\right)$ were calculated using 2017 University of Arkansas interactive crop production budget spreadsheets (University of Arkansas Cooperative Extension Service, 2017a) and actual 
Table 7. Average Operating Costs by Weed Management (\$/acre)

\begin{tabular}{lccc}
\hline \hline Operating Cost Item & $\begin{array}{l}\text { Low Weed } \\
\text { Management }\end{array}$ & $\begin{array}{l}\text { Medium Weed } \\
\text { Management }\end{array}$ & $\begin{array}{c}\text { High Weed } \\
\text { Management }\end{array}$ \\
\hline Fertilizer & 52.84 & 52.84 & 52.84 \\
Herbicide & 18.68 & 23.53 & 55.57 \\
Custom application & 24.55 & 17.55 & 22.22 \\
Machinery fuel & 14.56 & 14.72 & 14.72 \\
Machinery repairs and maintenance & 25.42 & 25.65 & 25.65 \\
Irrigation fuel & 66.25 & 66.25 & 66.25 \\
Labor & 12.39 & 12.51 & 12.51 \\
Interest & 4.51 & 4.47 & 5.25 \\
Total & 219.21 & 217.55 & 255.02 \\
\hline \hline
\end{tabular}

production inputs used in the study. Costs for imidazoline herbicides were not included in these budgets, as neither CLXL729 nor CL171AR were grown under "Clearfield" management protocols. Seed costs were also excluded from variable production costs for the same reason. Seed costs for Clearfield and Clearfieldhybrid cultivars are much more expensive than seed costs for non-Clearfield, nonhybrid pure line varieties. Average variable production expenses for the study are reported by expense item and weed management in Table 7 .

\subsection{Risk Analysis}

Following Bryant et al. (2008), SERF was used to rank rice cultivar-weed management combinations according to risk attitudes. The SERF method orders a set of risky alternatives in terms of CEs calculated for specified ranges of risk attitudes (Hardaker et al., 2004). A CE is equal to the amount of certain payoff an individual would require to be indifferent between that payoff and a risky investment. For a rational decision maker who is risk averse, the $\mathrm{CE}$ is typically less than the expected (mean) monetary value and greater than or equal to the minimum monetary value of a stream of monetary outcomes (Hardaker et al., 2004). Risky outcomes with higher CEs are preferred to those with lower CEs. Thus, graphical mapping of CEs of risky outcomes over a range of ARACs facilitates ordinal rankings for decision makers with different risk attitudes. Risk premiums may also be calculated using SERF analysis. Risk premiums are a cardinal measure of a decision maker's conviction for preferences among risky alternatives and may be calculated as the difference in CEs between two risky alternatives for a given level of risk aversion (Hardaker et al., 2004). A risk premium for a risk-averse decision maker represents the minimum amount of money a decision maker needs to be paid to switch from a preferred strategy to a less preferred strategy (Williams et al., 2012).

A utility function must be specified to calculate CEs. The utility function used most often with SERF analysis is the negative exponential utility function. 
This function is recommended by Hardaker et al. (2004) because it is a CARA (constant absolute risk aversion) function, and it can act as a reasonable approximation of the actual but unknown utility function. This function is appropriate provided the range of risky alternatives is small relative to the decision maker's wealth (Tsiang, 1972). The negative exponential utility function also conforms to the hypothesis that decision makers prefer less risk to more given the same expected return (Williams et al., 2012).

An appropriate range of ARACs must be specified for calculating CEs with the negative exponential utility function. The ARAC represents a decision maker's degree of risk aversion. Decision makers are risk averse if ARAC $>0$, risk neutral if $\mathrm{ARAC}=0$, and risk preferring if $\mathrm{ARAC}<0$. The ARAC values in this analysis ranged from 0 (risk neutral) to 0.0153 (strongly risk averse). The upper ARAC value was calculated using the following formula suggested by Hardaker et al. (2004):

$$
A R A C w=\frac{r_{r}(w)}{w}
$$

where $r_{r}(w)$ is the relative risk aversion coefficient with respect to a specified level of wealth $(w)$, and $A R A C_{w}$ equals the ARAC with respect to $w$. In this analysis, $r_{r}(w)$ was set to 4 (very risk averse) as proposed by Anderson and Dillon (1992), and $w$ was estimated as the average net return to production expenses for all seven cultivars under high weed management (\$261/acre).

The SERF procedure in SIMETAR is used to calculate CEs by rice cultivar and weed management using the ARAC ranges specified previously and a negative exponential utility function. Risk premiums of using high weed management over medium weed management are then calculated for each rice cultivar at alternative ARAC values to determine the amounts of money ( $\$ /$ acre) necessary to cause decision makers with varying levels of risk aversion to switch from more intensive herbicide management (high weed management) to less intensive herbicide management (medium weed management) and to determine if weedsuppressive rice cultivars might generate positive risk premiums using medium rather than high weed management. Mappings of CEs across ARAC values are then compared for the most dominant rice cultivar-weed management combinations to determine which cultivar-weed management combinations dominate overall based on SERF analysis.

\section{Results}

\subsection{Rice Cultivar by Weed Management Net Returns}

Summary statistics of simulated net returns to operating costs by rice cultivar and weed management scenario are presented in Table 8. Cultivars with the highest mean net returns are found in both high and medium weed management. The top five rice cultivar-weed management combinations ranked 
Table 8. Summary Statistics of Simulated Rice Net Returns to Operating Costs by Cultivar and Weed Management (\$/acre)

\begin{tabular}{lccccc}
\hline \hline Cultivar & Mean $^{\text {a }}$ & SD & CV & Minimum & Maximum \\
\hline \multicolumn{2}{l}{ High Weed Management } & & & & \\
PI 312777 & 291 & 107 & 37 & 53 & 506 \\
Rondo & 224 & 73 & 33 & 64 & 409 \\
CLXL729 & 406 & 146 & 36 & 48 & 608 \\
Bengal & 261 & 174 & 67 & -1 & 561 \\
Wells & 297 & 109 & 37 & 134 & 528 \\
Lemont & 164 & 117 & 71 & 7 & 445 \\
CL171AR & 183 & 95 & 52 & -27 & 357 \\
Medium Weed Management & & & & \\
PI 312777 & 316 & 120 & 38 & 120 & 641 \\
Rondo & 240 & 83 & 34 & 83 & 418 \\
CLXL729 & 333 & 182 & 55 & -58 & 487 \\
Bengal & 246 & 168 & 68 & -72 & 545 \\
Wells & 267 & 151 & 57 & 26 & 248 \\
Lemont & 72 & 92 & 127 & -120 & 355 \\
CL171AR & 116 & 130 & 112 & -85 & \\
Low Weed Management & & & & & 452 \\
PI 312777 & 161 & 148 & 92 & -120 & 348 \\
Rondo & 44 & 102 & 229 & -118 & 312 \\
CLXL729 & 82 & 177 & 217 & -137 & 244 \\
Bengal & 6 & 150 & 2362 & -208 & -18 \\
Wells & -17 & 134 & -774 & -216 & 290 \\
Lemont & -137 & 58 & -42 & -212 & -210 \\
CL171AR & -62 & 147 & -236 & & \\
\hline \hline
\end{tabular}

${ }^{a}$ Summary statistics calculated from 500 simulated iterations.

Note: CV, coefficient of variation; SD, standard deviation.

in order of largest mean net returns are as follows: CLXL729 under high weed management (\$406/acre), CLXL729 under medium weed management (\$333/acre), PI 312777 under medium weed management (\$316/acre), Wells under high weed management (\$297/acre), and PI 312777 under high weed management (\$291/acre). All five of the top ranking cultivars tend to have relatively low return variability as measured by their coefficients of variation, with values ranging from 36 for CLXL723/high weed management to 55 for CLXL723/medium weed management.

CLXL729 had the largest mean returns under both high and medium weed management. This is attributable in large part to CLXL729 having the largest mean yield of the seven cultivars under high weed management (Table 2) and a better mean milling yield adjusted rice price than the highest yielding cultivar PI 312777 under medium weed management (Table 6). PI 312777 had the second largest return under medium weed management and the third largest return under high weed management. PI 312777 is a weed-suppressive cultivar with allopathic activity via potent phytotoxic allelochemicals released by its roots 
(Gealy, Moldenhauer, and Jia, 2013). PI 312777 has the largest numeric mean yield of the seven rice cultivars under medium weed management and the second largest mean yield (tied with Rondo) under high weed management. PI 312777 also has the largest mean yield of the seven rice cultivars evaluated under low weed management (Table 2). The higher relative yields of PI 312777 under both medium and low weed management provide evidence of higher weed-suppressive ability for PI 312777 relative to the other rice cultivars evaluated in the analysis.

The net return summary statistics in Table 8 reveal that some cultivars appear to be less dependent on herbicide inputs than others to achieve maximum average returns. Mean net returns for the weed-suppressive cultivars PI 312777 and Rondo are largest under medium weed management, whereas mean net returns for the other five cultivars are largest under high weed management. The relative net return variability of PI 312777 and Rondo as measured by each cultivar's coefficient of variation is also relatively equal under either high or medium weed management. Conversely, the cultivar Lemont has the lowest mean net returns and the largest coefficients of variation for all three weed management strategies and the smallest net return under low weed management $(-\$ 137 /$ acre $)$. The average yields for Lemont are numerically smaller than those of the other six rice cultivars under all three weed management levels (Table 2), implying that Lemont is the least weed-suppressive rice cultivar in the study.

CLXL729 is also classified as a weed-suppressive rice cultivar in this study, but CLXL729 may exhibit less weed-suppressive ability than either PI 312777 or Rondo based on its mean net returns. Mean net returns were maximized for CLXL729 using high weed management, indicating that CLXL729 requires more herbicide inputs than either Rondo or PI 312777 to achieve higher profitability. This result is likely because of lower seeding rates used for commercial hybrids like CLXL729 relative to nonhybrid cultivars. Hybrid rice seed is much more expensive than nonhybrid rice seed, and hybrids are planted at much lower seeding rates $(21$ to $31 \mathrm{lb}$./acre for hybrids vs. 50 to $120 \mathrm{lb}$./acre for nonhybrids, depending on soil conditions and cultivar (Hardke, 2016). In this study, CLXL729 was planted using a seeding rate of $30.5 \mathrm{lb}$./acre. The lower seeding rate results in a lower plant stand with fewer rice plants competing with weeds and more time required for rice canopy closure after planting, making CLXL729 potentially more susceptible to early weed pressures compared with either PI 312777 or Rondo. However, CLXL729 produces the largest numeric mean net returns under both medium or high weed management (\$333/acre and\$406/acre, respectively) and the third largest numeric mean net return under low weed management (\$82/acre, Table 8). Thus, CLXL729 may still be considered more weed suppressive than Bengal, Wells, Lemont, and CL171AR but less weedsuppressive than either PI 312777 or Rondo.

Net return probability intervals by rice cultivar under medium and high weed management based on 500 iterations are presented in Figure 1. The probability interval of net returns less than $\$ 0 /$ acre represents the probability of receiving 


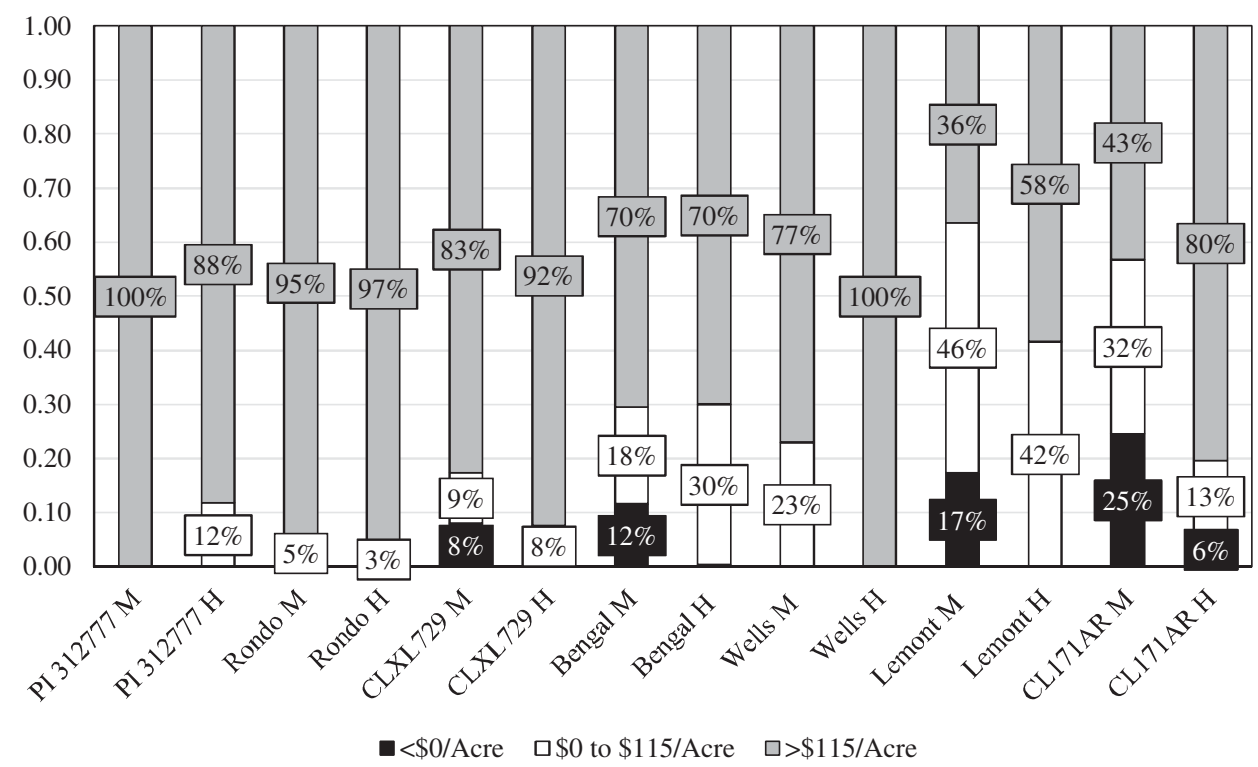

Figure 1. Net Return Probability Intervals by Rice Cultivar under Medium and High Weed Management Based on 500 Iterations ( $\mathrm{H}$, high weed management; $\mathrm{M}$, medium weed management)

a negative return (e.g., the probability that gross returns do not cover variable costs). The probability interval of net returns greater than $\$ 115 /$ acre represents the probability of gross returns covering both variable and fixed costs, with fixed costs across all cultivar-weed management combinations in the study equaling $\$ 115 /$ acre. This interval would represent the probability of receiving favorable or exceptional returns. Finally, the probability interval of net returns between $\$ 0$ and $\$ 115 /$ acre represents the probability of achieving gross returns covering variable costs.

Rice cultivar-weed management combinations with the largest probabilities of receiving favorable net returns in excess of $\$ 115 /$ acre are PI $312777 \mathrm{M}$ and Wells H (100\% each), Rondo H (97\%), Rondo M (95\%), CLXL729 H (92\%), and PI 312777 (88\%). Thus, the cultivars with the highest probabilities of achieving favorable returns are the weed-suppressive cultivars PI 312777 and Rondo under either high $(\mathrm{H})$ or medium $(\mathrm{M})$ weed management, the Clearfield-hybrid cultivar CLXL729 under either high or medium weed management, and the long-grain cultivar Wells under high weed management. Rice cultivar-weed management combinations with the largest probabilities of receiving negative net returns include CL171AR M (25\%), Lemont M (17\%), Bengal M (12\%), CL171AR $\mathrm{M}(8 \%)$, and CL171AR H (6\%). 
Table 9. Certainty Equivalents by Rice Cultivar-Weed Management Combination and Risk Premiums of High over Medium Weed Management by Rice Cultivar for Various Absolute Risk Aversion Coefficients Assuming a Negative Exponential Utility Function

\begin{tabular}{|c|c|c|c|c|c|}
\hline \multirow{2}{*}{$\begin{array}{l}\text { Cultivar and Weed } \\
\text { Management }\end{array}$} & \multicolumn{5}{|c|}{ Absolute Risk Aversion Coefficients } \\
\hline & 0.0000 & 0.0038 & 0.0077 & 0.0115 & 0.0153 \\
\hline \multicolumn{6}{|c|}{ Certainty Equivalents (\$/acre) } \\
\hline PI $321777 \mathrm{H}^{\mathrm{a}}$ & 291 & 267 & 243 & 219 & 199 \\
\hline PI $321777 \mathrm{M}$ & 316 & 290 & 268 & 251 & 237 \\
\hline PI $321777 \mathrm{~L}$ & 161 & 117 & 74 & 39 & 12 \\
\hline Rondo H & 224 & 214 & 206 & 198 & 191 \\
\hline Rondo M & 240 & 227 & 215 & 205 & 195 \\
\hline Rondo L & 44 & 27 & 12 & 0 & -11 \\
\hline CLXL729 H & 406 & 359 & 306 & 259 & 223 \\
\hline CLXL729 M & 333 & 263 & 195 & 143 & 107 \\
\hline CLXL729 L & 82 & 35 & 8 & -10 & -23 \\
\hline Bengal H & 261 & 206 & 164 & 135 & 115 \\
\hline Bengal M & 246 & 188 & 136 & 96 & 69 \\
\hline Bengal L & 6 & -32 & -60 & -80 & -95 \\
\hline Wells $\mathrm{H}$ & 297 & 276 & 258 & 244 & 233 \\
\hline Wells M & 267 & 224 & 188 & 161 & 141 \\
\hline Wells L & -17 & -51 & -80 & -103 & -121 \\
\hline Lemont $\mathrm{H}$ & 164 & 141 & 123 & 110 & 100 \\
\hline Lemont $\mathrm{M}$ & 72 & 56 & 41 & 26 & 13 \\
\hline Lemont L & -137 & -143 & -149 & -154 & -158 \\
\hline CL171AR H & 183 & 165 & 145 & 127 & 110 \\
\hline CL171AR M & 116 & 86 & 61 & 43 & 29 \\
\hline CL171AR L & -62 & -95 & -115 & -128 & -138 \\
\hline \multicolumn{6}{|c|}{ Risk Premiums of High over Medium Weed Management (\$/acre) } \\
\hline PI 312777 & -25 & -22 & -25 & -32 & -38 \\
\hline Rondo & -16 & -13 & -10 & -7 & -5 \\
\hline CLXL729 & 73 & 96 & 111 & 116 & 116 \\
\hline Bengal & 15 & 18 & 29 & 39 & 46 \\
\hline Wells & 30 & 51 & 69 & 83 & 92 \\
\hline Lemont & 92 & 85 & 83 & 84 & 87 \\
\hline CL171AR & 67 & 79 & 84 & 84 & 81 \\
\hline
\end{tabular}

${ }^{\mathrm{a}} \mathrm{H}$, high weed management; L, low weed management; $\mathrm{M}$, medium weed management.

\subsection{Certainty Equivalents and Risk Premiums}

CEs by rice cultivar-weed management combination are presented for various ARACs in Table 9. CEs are equal to the mean net return when ARAC $=0$ (risk neutrality) but decline as ARACs become larger (e.g., as risk aversion increases). The rice cultivars CLXL729, Bengal, Wells, Lemont, and CL171AR have the largest CEs across ARACs under high weed management. Thus, high weed management dominates medium weed management for these five cultivars. Alternatively, CEs are largest for the two weed-suppressive cultivars PI 312777 
and Rondo under medium weed management across ARACs, indicating medium weed management dominates high weed management for these two cultivars.

Risk premiums of high over medium weed management are also presented for various ARACs in Table 6. Risk premiums of high over medium weed management are positive for CLXL729, Bengal, Wells, Lemont, and CL171AR across all ARACs. Thus risk-averse decision makers growing these five rice cultivars would need to receive some minimum level of payoff to choose medium weed management over high weed management. Risk premiums of high over medium weed management are largest with CLXL729 as risk aversion increases, implying risk-averse decision makers would need much larger minimum payoffs for ClXL729 than for Bengal, Wells, Lemont, or CL171AR to use medium weed management over high weed management. Risk premiums of high over medium weed management are negative across all ARACs for PI 312777 and Rondo, indicating these two rice cultivars actually exhibit positive risk premiums for using medium weed management over high weed management. Therefore, riskaverse decision makers growing either PI 312777 or Rondo would need to receive some positive minimum level of payoff to choose high weed management over medium weed management.

\subsection{Stochastic Efficiency with Respect to a Function Results}

CEs for the best rice cultivar-weed management combinations are mapped across ARACs in Figure 2. ARACs in Figure 2 range from 0 (risk neutral) to 0.0153 (strong risk aversion), and combinations having the locus of points of highest CE values are risk preferred to other combinations. Based on this criteria, the three most dominant rice cultivar-weed management combinations are CLXL729 H, PI $312777 \mathrm{M}$, and Wells H. Both PI $312777 \mathrm{M}$ and Wells $\mathrm{H}$ cross CLXL729 $\mathrm{H}$ at ARAC $=0.0128$ and ARAC $=0.0141$, respectively. Beyond these respective ARAC values, both PI $312777 \mathrm{M}$ and Wells $\mathrm{H}$ dominate CLXL729 H. PI $312777 \mathrm{M}$ dominates Wells $\mathrm{H}$ across all ARAC values. Thus, a grouping of both CLXL729 H and PI $312777 \mathrm{M}$ would dominate all other rice cultivar-weed management combinations based on SERF analysis, with the inflection point occurring at $\mathrm{ARAC}=0.0128$. The worst rice cultivar-weed management combination based on SERF analysis is Lemont H. Its mapping of $\mathrm{CE}$ values across absolute risk aversion is lowest among the seven best cultivarweed management combinations in Figure 2.

Finally, SERF analysis was performed on the net return distributions of the seven rice cultivars under low weed management to determine how each cultivar faired under high weed pressure. These results are presented in Figure 3. Three rice cultivars dominate all others under low weed management. These are PI 312777, CLXL729, and Rondo. The allelopathic cultivar PI 312777 dominates both CLXL729 and Rondo, and its CEs under low weed management are positive across all ARACs. These findings indicate PI 312777 may have potential for use in reduced-input rice systems. 


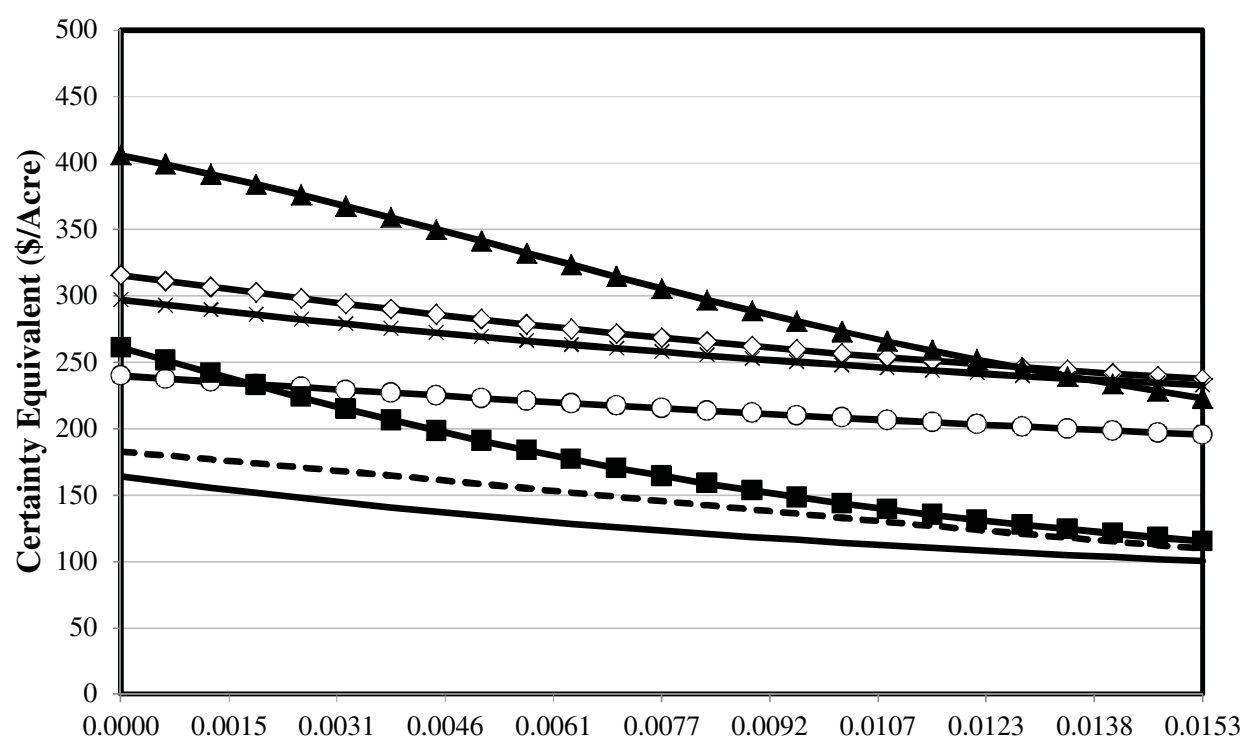

Absolute Risk Aversion Coefficient

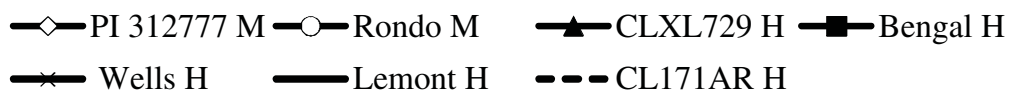

Figure 2. Stochastic Efficiency with Respect to a Function Results of Best CultivarWeed Management Combinations over an Absolute Risk Aversion Range of 0.0000 to 0.0153 and Assuming a Negative Exponential Utility Function $(\mathrm{H}$, high weed management; $M$, medium weed management)

\section{Summary and Conclusions}

This study uses simulation and SERF to evaluate the profitability and risk preferences of using weed-suppressive rice cultivars in rice production. The study uses grain yields, production inputs, and herbicide application data from a 3-year agronomic study conducted during the years 2009, 2010, and 2011. Rice grain yields and rice prices adjusted for milling quality are simulated for seven different rice cultivars under three levels of weed management (high, medium, and low). Distributions of net returns above production costs are constructed, and SERF analysis is used to rank rice cultivar-weed management combinations under risk aversion and to calculate risk premiums for each cultivar using high (medium) over medium (high) weed management.

The results identify the rice cultivars CLXL729 and PI 312777 as the most profitable of the seven cultivars evaluated. Both cultivars exhibit high yields under both high and medium weed management. CLXL729 had the largest mean net returns under both high and medium weed management, while PI 312777 


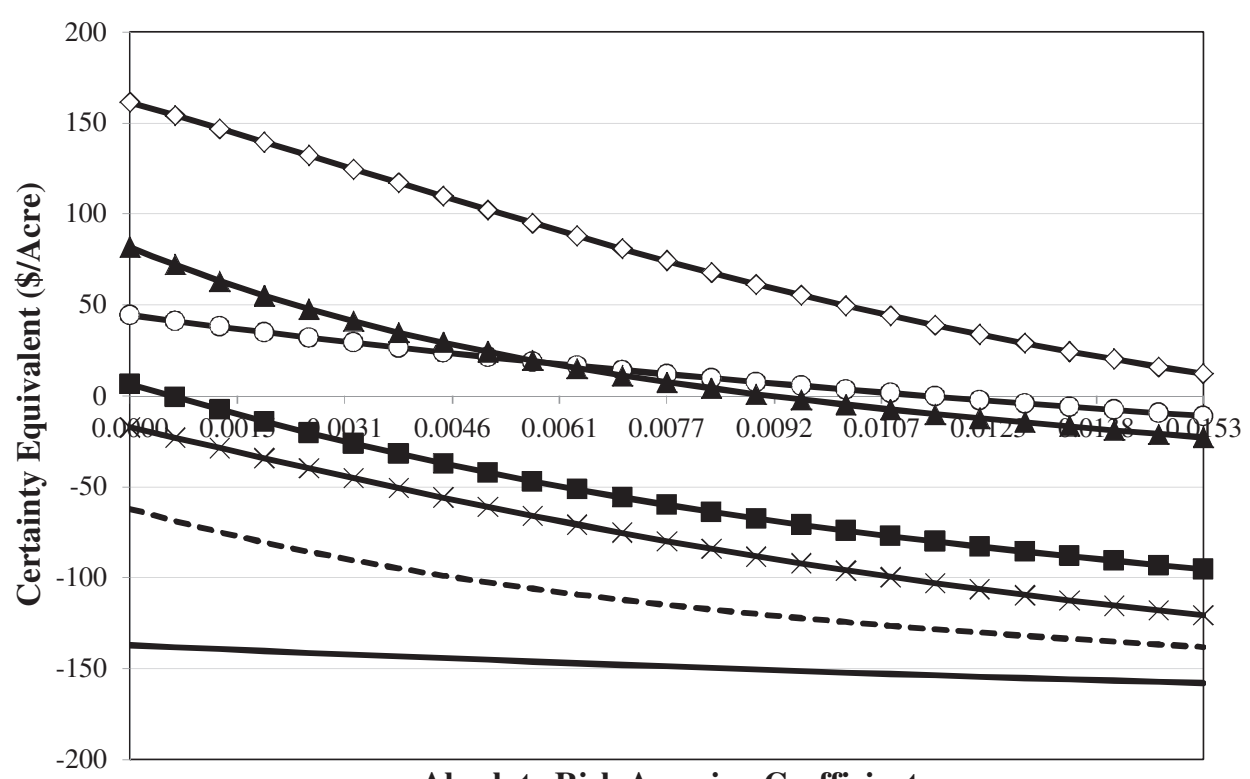

Absolute Risk Aversion Coefficient

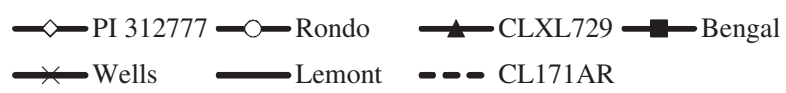

Figure 3. Stochastic Efficiency with Respect to a Function Results of Rice Cultivars under Low Weed Management over an Absolute Risk Aversion Range of 0.0000 to 0.0153 and Assuming a Negative Exponential Utility Function

had the second largest mean net return under medium weed management. A combination of both cultivars was found by SERF analysis to dominate the remaining five cultivars evaluated in the study (Wells, Bengal, Rondo, Lemont, and CL171AR). Both CLXL729 and PI 312777 also preformed well under medium weed management. Thus, both rice cultivars have potential for use in aerobic rice systems, which often exhibit higher weed pressures when compared with conventional flooded (anaerobic) rice systems. Examples of such systems include furrow (row) rice and intermittent flooded rice.

SERF analysis was also conducted for all seven rice cultivars under low weed management to determine if particular cultivars performed better economically in a high weed pressure setting. SERF analysis indicated PI 312777, CLXL729, and Rondo dominated the other four cultivars (Bengal, Wells, CL171AR, and Lemont) when weed pressure was high. PI 312777 in particular had positive CEs across all levels of absolute risk aversion under low weed management, indicating this variety may have potential for use in reduced-input rice production systems that are particularly vulnerable to high weed pressure. One such rice 
system is organic rice, which excludes all synthetic inputs including synthetic herbicides.

The results also provide evidence that weed-suppressive cultivars can achieve greater profitability by using less herbicide inputs relative to weednonsuppressive rice cultivars. The weed-suppressive rice cultivars PI 312777 and Rondo both had larger mean net returns under medium weed management when compared with high weed management. Thus, risk-neutral decision makers growing either of these two cultivars would prefer using medium weed management (using less herbicide inputs) over high weed management (using more herbicide inputs). The SERF analysis indicates risk-averse decision makers growing either of these two weed-suppressive cultivars would also prefer using medium over high weed management, as the mapping of CEs across increasing levels of absolute risk aversion are higher for both PI 312777 and Rondo under medium versus high weed management. Risk premiums for using medium over high weed management are also positive across all levels of absolute risk aversion for these two rice cultivars. Opposite results are found for the remaining five cultivars evaluated in the analysis (CLXL729, Bengal, Wells, Lemont, and CL171AR). These results provide evidence that weed-suppressive rice cultivars have the potential to reduce heavy reliance on herbicides in rice production.

As with Gealy et al. (2003), we adjusted gross returns for each rice cultivar to reflect differences in milling quality. The two weed-suppressive cultivars PI 312777 and Rondo have lower milling quality relative to the other five cultivars evaluated in the analysis. Gealy et al. (2003) found low milling quality reduced the economic gains of weed-suppressive rice cultivars because lower milling quality leads to lower rice prices and thus lower relative gross returns. We found the allelopathic rice cultivar PI 312777 to be relatively as profitable as other weed-nonsuppressive rice cultivars despite having lower milling quality. This finding may be attributable in large part to differences in average milling yields reported for PI 312777 in both studies. The average percent head and broken yields for PI 312777 in our study were $49.7 \%$ and $19.2 \%$, respectively, based on 3 years of replicated data from Texas. This compares with average percent head and broken yields reported by Gealy et al. (2003) for PI 312777 of $45 \%$ and $25 \%$, respectively, based on field tests conducted in Arkansas in the late 1990s. The average price for PI 312777 in our analysis is $\$ 5.32 /$ bu. The average estimated price for PI 312777 using the milling yields reported by Gealy et al. (2003) and using the whole kernel and broken kernel prices used in our present study ( $\$ 8.70 / \mathrm{bu}$. and $\$ 5.22 / \mathrm{bu}$., respectively) is $\$ 5.22 / \mathrm{bu}$. Consequently, the value for PI 312777 in our study is larger on average than it would be using the average milling yields reported by Gealy et al. (2003). The major difference between our analysis and Gealy et al. (2003) is that rice prices in our study are stochastic with regard to milling yields, whereas rice prices in Gealy et al. (2003) are estimated using average milling yields. 


\section{References}

Anderson, J.R., and J.L. Dillon. Risk Analysis in Dryland Farming Systems. Farming Systems Management Series No. 2. Rome, Italy: Food and Agriculture Organization of the United Nations, 1992.

Bollich, C.W., B.D. Webb, M.A. Marchetti, and J.E. Scott. "Registration of 'Lemont' Rice." Crop Science 25,5(1985):883-85.

Bryant, K.J., J.M. Reeves, R.L. Nichols, J.K. Greene, C.H. Tingle, G.E. Studebaker, F.M. Bourland, C.D. Capps Jr., and F.E. Groves. "Valuing Transgenic Cotton Technologies Using a Risk/Return Framework.” Journal of Agricultural and Applied Economics 40,3(2008):767-75.

Chen, X.H., F. Hu, and C.H. Kong. "Varietal Improvements in Rice Allelopathy." Allelopathy Journal 22,2(2008):379-84.

Duke, S.O., F.E. Dayan, J.G. Romagni, and A.M. Rimando. "Natural Products as Sources of Herbicides: Current Status and Future Trends." Weed Research 40,1(2000): 99-111.

Gealy, D.R., M. Anders, B. Watkins, and S. Duke. "Crop Performance and Weed Suppression by Weed-Suppressive Rice Cultivars in Furrow- and Flood-Irrigated Systems under Reduced Herbicide Inputs.” Weed Science 62,2(2014):303-20.

Gealy, D.R., and K.A.K. Moldenhauer. "Use of ${ }^{13} \mathrm{C}$ Isotope Discrimination Analysis to Quantify Distribution of Barnyardgrass and Rice Roots in a Four-Year Study of WeedSuppressive Rice.” Weed Science 60,1(2012):133-42.

Gealy, D.R., K.A.K. Moldenhauer, and M.H. Jia. "Field Performance of STG06L-35-061, a New Genetic Resource Developed from Crosses between Weed-Suppressive Indica Rice and Commercial Southern U.S. Long-Grains.” Plant Soil 370,1-2(2013):277-93.

Gealy, D.R., E.J. Wailes, L.E. Estorninos Jr., and R.S.C. Chavez. "Rice Cultivar Differences in Suppression of Barnyardgrass (Echinochioa crus-galli) and Economics of Reduced Propanil Rates.” Weed Science 51,4(2003):601-9.

Gealy, D.R., and W. Yan. "Weed Suppression Potential of 'Rondo' and Other Indica Rice Germplasm Lines.” Weed Technology 26,3(2012):517-24.

Guo, Y., N. Ahmad, D. Shin, and K.U. Kim. "Allelopathic Effects of Rice Cultivars on Barnyardgrass Growth to Reduce the Herbicide Dose." Allelopathy Journal 24,2(2009):321-30.

Hardaker, J.B., J.W. Richardson, G. Lien, and K.D. Schumann. "Stochastic Efficiency Analysis with Risk Aversion Bounds: A Simplified Approach.” Australian Journal of Agricultural and Resource Economics 48,2(2004):253-70.

Hardke, J. Rice Information: RICESEED Update 2016. University of Arkansas System Division of Agriculture, Cooperative Extension Service, 2016. Internet site: http://www.uaex.edu/farm-ranch/crops-commercial-horticulture/rice/Riceseed\% 20Update\%202016.pdf (Accessed November 27, 2017).

He, H.B., H.B. Wang, C.X. Fang, Y.Y. Lin, C.M. Zeng, L.Z. Wu, W.C. Guo, and W.X. Lin. "Herbicidal Effect of a Combination of Oxygenic Terpenoids on Echinochloa crusgalli." Weed Research 49,2(2009):183-92.

Khanh, T.D., T.D. Zuan, and I.M. Chung. "Rice Allelopathy and the Possibility for Weed Management." Annals of Applied Biology 151,3(2007):325-39.

Kong, C.H., X.H. Chen, F. Hu, and S.Z. Zhang. "Breeding of Commercially Acceptable Allelopathic Rice Cultivars in China.” Pest Management Science 67,9(2011):11001106. 
Kong, C.H., F. Hu, P. Wang, and J.-L. Wu. "Effect of Allelopathic Rice Varieties Combined with Cultural Management Options on Paddy Field Weeds.” Pest Management Science 64,3(2008):276-82.

Linscombe, S.D., F. Jodari, K.S. McKenzie, P.K. Bollich, L.M. White, D.E. Groth, and R.T. Dunand. "Registration of 'Bengal' Rice." Crop Science 33,3(1993): 645-46.

Moldenhauer, K.A.K., F.N. Lee, J.L. Bernhardt, R.J. Norman, N.A. Slaton, C.E. Wilson, M.M. Anders, R.D. Cartwright, and M.M. Blocker. "Registration of 'Wells' Rice." Crop Science 47,1(2007):442-43.

Pendell, D.L., J.R. Williams, C.W. Rice, R.G. Nelson, and S.B. Boyles. "Economic Feasibility of No-Tillage and Manure for Soil Carbon Sequestration in Corn Production in Northeastern Kansas." Journal of Environmental Quality 35,4(2006): 1364-73.

Pheng, S., M. Olofsdotter, G. Jahn, H. Nesbit, and S.W. Adkins. "Allelopathic Potential of Cambodian Rice Lines under Field Conditions." Weed Biology and Management 9,4(2009):267-75.

Ribera, L.A., E.M. Hons, and J.W. Richardson. "An Economic Comparison between Conventional and No-Tillage Farming Systems in Burleson County, Texas.” Agronomy Journal 96,2(2004):415-24.

Richardson, J.R., S.L. Klose, and A.W. Gray. “An Applied Procedure for Estimating and Simulating Multivariate Empirical (MVE) Probability Distributions in Farm-Level Risk Assessment and Policy Analysis." Journal of Agricultural and Applied Economics 32,2(2000):299-315.

Richardson, J.R., K.D. Schumann, and P.A. Feldman. SIMETAR@: Simulation and Econometrics to Analyze Risk. College Station: Agricultural and Food Policy Center, Department of Agricultural Economics, Texas A\&M University, 2008.

Saito, K. "A Screening Protocol for Developing High-Yielding Upland Rice Varieties with Superior Weed-Suppressive Ability.” Field Crops Research 168(November 2014):119_ 25.

Saito, K., and K. Futakuchi. "Improving Estimation of Weed-Suppressive Ability of Upland Rice Varieties using Substitute Weeds." Field Crops Research 162(June 2014): $1-5$.

Scott, R.C., J.W. Boyd, K.L. Smith, G. Selden, and J.K. Norsworthy. Recommended Chemicals for Weed and Brush Control. MP44. Little Rock, AR: University of Arkansas Extension and U.S. Department of Agriculture, 2012.

Tsiang, S.C. "The Rationale of the Mean-Standard Deviation Analysis, Skewness Preference, and the Demand for Money." American Economic Review 62,3(1972): 354-71.

University of Arkansas Cooperative Extension Service. "2017 Interactive Budgets: Rice." 2017a. Internet site: https://www.uaex.edu/farm-ranch/economics-marketing/farmplanning/budgets/crop-budgets.aspx (Accessed September 8, 2017).

University of Arkansas Cooperative Extension Service. "Results of Arkansas Rice Cultivar Testing.” 2017b. Internet site: https://www.uaex.edu/farm-ranch/cropscommercial-horticulture/rice/ (Accessed September 20, 2017).

U.S. Department of Agriculture, National Agricultural Statistics Service. "Quick Stats" [searchable database]. 2018. Internet site: https://quickstats.nass.usda.gov/ (Accessed January 31, 2018). 
Williams, J.R., M.J. Pachta, K.L. Roozeboom, R.V. Llewelyn, M.M. Claassen, and J.S. Bergtold. "Risk Analysis of Tillage and Crop Rotation Alternatives with Winter Wheat." Journal of Agricultural and Applied Economics 44,4(2012):561-76.

Worthington, M., and C. Reberg-Horton. "Breeding Cereal Crops for Enhanced Weed Suppression: Optimizing Allelopathy and Competitive Ability." Journal of Chemical Ecology 39,2(2013):213-31.

Xuan, T.D., T. Eiji, T. Shinkichi, and T.D. Khanh. "Methods to Determine Allelopathic Potential of Crop Plants for Weed Control.” Allelopathy Journal 13,2(2004):149-64.

Yan, W.G., and A.M. McClung. "'Rondo', a Long-Grain Indica Rice with Resistance to Multiple Diseases.” Journal of Plant Registrations 4,2(2010):131-36. 